\title{
Características da chuva e perdas por erosão sob diferentes práticas de manejo do solo ${ }^{1}$
}

\author{
Daniel F. de Carvalho ${ }^{2}$, Eleandro S. da Cruz $^{3}$, Marinaldo F. Pinto ${ }^{4}$, Leonardo D. B. Silva ${ }^{2}$ \& José G. M. Guerra ${ }^{5}$
}

\begin{abstract}
RESUMO
Objetivou-se com este trabalho, avaliar as relações entre a erosividade da chuva e os padrões da precipitação com as perdas por erosão, para diferentes tipos de preparo do solo em um Argissolo Vermelho-Amarelo. O experimento foi conduzido utilizando-se parcelas experimentais de perda de solo com dimensões de 3,5 x 22,0 m, com os seguintes tratamentos: preparo convencional do solo em nível e semeadura de Mucuna Cinza (Mucuna pruriens), Crotalária (Crotalaria juncea), e Milho (Zea mays L.); preparo convencional do solo no sentido do declive e semeadura de miIho no mesmo sentido e preparo convencional do solo no sentido do declive, mantido sem qualquer tipo de cobertura. Foi possível evidenciar que as perdas de solo foram mais influenciadas pelos diferentes tratamentos que as perdas de água; os tratamentos Crotalária e Milho morro abaixo, foram aqueles que apresentaram, respectivamente, as menores e maiores perdas de solo e água e, em média, os eventos de precipitação caracterizados como avançado, intermediário e atrasado, foram responsáveis por $62,6,11,8$ e 25,6\% das perdas de água e por $35,1,6,6$ e 58,3\% das perdas de solo, respectivamente.
\end{abstract}

Palavras-chave: chuvas erosivas, perda de solo, perda de água, escoamento superficial

\section{Rainfall characteristics and erosion losses for different soil management practices}

\begin{abstract}
This study was carried out in order to evaluate the relation between erosivity index and the rainfall pattern associated with different kinds of soil preparation and cover with erosion losses in a Red Yellow Argisol. The experiment was conducted in five soil loss experimental plots of $3.5 \times 22.0 \mathrm{~m}$, with the following treatments: conventional tillage (plowing plus disking) in contour lines and sowing the velvet bean (Mucuna pruriens), sun hemp (Crotalaria juncea) and corn (Zea mays L.); conventional tillage (plowing plus disking) in slope line and sowing of corn, conventional tillage (plowing plus disking) in slope line and without soil cover. The results showed that soil loss was more affected by different treatments than water loss; the treatments sun hemp and corn sowed in slope line were those that presented, respectively, the smaller and the larger soil and water losses; and the precipitation events characterized as advanced, intermediate and delayed patterns were responsible for $62.6,11.8$ and $25.6 \%$ of the water losses and for $35.1,6.6$ and $58.3 \%$ of the soil losses, respectively.
\end{abstract}

Key words: erosive rainfall, soil loss, water loss, runoff

\footnotetext{
Extraído da Dissertação de Mestrado do $2^{\circ}$ autor, apresentada ao Curso de Agronomia - Ciência do Solo da UFRRJ

2 DE/UFRRJ. BR 465, km 7, CEP 23890-000, Seropédica, RJ. E-mail: carvalho@ufrrj.br (Bolsista do CNPq); irriga@ufrrj.br

3 INCRA, Rua 08, Quadra 15, CEP 78050-000, Cuiabá, MT. Fone: (65) 3644-1104. E-mail: eleandro.cruz@cba.incra.gov.br

${ }^{4}$ IT/DE/UFRRJ. Fone: (21) 3787-3674. E-mail: mfpufrij@yahoo.com.br. Bolsista de Iniciação Científica da FAPERJ.

${ }^{5}$ CNPAB. BR 465, Km 7, CEP 23890-000, Seropédica, RJ. Fone: (21) 2682-1500. E-mail: jmguerra@cnpab.embrapa.br (Bolsista do CNPq)
} 


\section{INTRODUÇÃO}

Erosão é o processo de desprendimento e arraste das partículas do solo causado pela água e pelo vento; entre os fatores que influenciam na magnitude do processo erosivo, estão as chuvas, a infiltração, a topografia do terreno, a cobertura vegetal e a natureza do solo (Bertoni \& Lombardi Neto, 2005). A erosão do solo, portanto, é um processo complexo que envolve vários fatores, de forma e magnitude variáveis, conforme o local de ocorrência.

O processo de erosão resulta de duas formas de ocorrência: da erosão em entressulcos e da erosão em sulcos, dependendo das condições superficiais em que ocorrem e da forma de atuação do agente erosivo (Silva et al., 2005). Segundo Pereira et al. (2003), a erosão em entressulcos é descrita como o processo de desprendimento das partículas de solo pelo impacto das gotas da chuva, seguido do transporte das partículas pelo escoamento superficial e pela deposição dos sedimentos nos pequenos sulcos ou canais; desta forma, a presença de resíduos vegetais no solo aumenta a rugosidade da superfície do terreno, reduzindo a velocidade de escoamento e possibilitando o aumento da infiltração da água no solo (Foster, 1982). A erosão no sulco é resultante do acúmulo da enxurrada em pequenas irregularidades no sentido do declive do terreno, a ponto de atingir volume e velocidade suficientes para formar canais mais ou menos profundos (Bertoni \& Lombardi Neto, 2005). Esta forma de erosão é função da capacidade do escoamento em desprender os sedimentos, da capacidade de transporte do escoamento e da carga de sedimentos existentes no escoamento, em que a maior parte do solo é perdida em pequenos sulcos que se formam em decorrência do escoamento superficial; esta é, também, a maneira de erosão mais característica e por isso mesmo mais percebida em áreas submetidas ao processo erosivo.

Em termos globais, a erosão do solo contabiliza, por ano, aproximadamente $190 \times 10^{9} \mathrm{t}$ de sedimentos, sendo que $10 \%$ desse montante são transportados para os oceanos (Lal, 1995). Estima-se que durante os últimos 40 anos cerca de $1 /$ 3 do total das terras aráveis do mundo foi permanentemente danificado pela erosão e continua sendo, embora a uma razão de 10 x $10^{6}$ ha ano-1 (Pimental et al., 1995).

Frente à importância que o fenômeno apresenta, muitos estudos têm sido realizados no intuito de se avaliar como os diferentes tipos de manejo do solo têm influenciado nas perdas por erosão (Vinsentin et al., 2002; Cassol \& Lima, 2003; Andrello et al., 2003; Cassol et al., 2004; Atreya et al., 2005; Bertol et al., 2003, 2004; Leite et al., 2004).

A degradação dos solos brasileiros está relacionada ao esgotamento da fertilidade do solo e à ocorrência do processo de erosão acelerada, dentre outros fatores (Bertoni \& Lombardi Neto, 2005); assim, técnicas agrícolas que promovam o aumento da cobertura e a ciclagem de nutrientes, devem ser empregadas no intuito de se utilizar este recurso natural de forma racional (Cassol et al., 2004; Tolk et al., 1999; Nuñes et al., 2003).

Diversas são as técnicas disponíveis para se manejar o solo de forma viável econômica e ambientalmente, mas o uso de técnicas inadequadas pode proporcionar a inutilização permanente de áreas para a exploração agrícola (Cruz, 2006). Neste sentido, a utilização de plantas em cobertura surge como alternativa para a manutenção da qualidade do solo, sendo capazes de reduzir a intensidade do processo erosivo podendo, inclusive, promover o restabelecimento de suas condições físicas e químicas.

Tendo em vista ser a chuva um dos principais agentes ativos no processo da erosão hídrica, é de extrema importância avaliar a resposta do solo às diferentes precipitações, tanto em termos do volume precipitado quanto pela duração e característica do evento. A chuva tem o potencial erosivo quantificado a partir de suas características físicas (volume total, duração e intensidade), sendo os índices de erosividade $\mathrm{EI}_{30}$ e $\mathrm{KE}>25$ os mais utilizados (Carvalho et al., 2005). Associado ao potencial erosivo, o perfil dessas precipitações se torna elemento fundamental nos estudos de perda de solo, uma vez que as características das chuvas mudam de região para região (Flanagan et al., 1988).

Carvalho et al. (2002), estudando as perdas de solo e água para diferentes energias cinéticas de chuvas simuladas, encontraram valores de perda que variaram 2,83 a 26,82 $\mathrm{g} \mathrm{m}^{-2}$ (solo) e de 0,00209 a $0,01370 \mathrm{~m}^{3} \mathrm{~m}^{-2}$ (água), quando a energia cinética da chuva variou de 138 para $321 \mathrm{~J} \mathrm{~m}^{-2}$, respectivamente. Utilizando chuva simulada, Oliveira (2007) estudou o efeito de quatro diferentes perfis de precipitação e duas condições de cobertura do solo no processo erosivo de um Argissolo Vermelho-Amarelo e constatou que os perfis de precipitação caracterizados como avançado, intermediário e atrasado proporcionaram maiores valores de perda de solo e água que o perfil constante e, ainda, que a cobertura do solo com resíduos da cultura do milho reduziu substancialmente as taxas e perdas de solo, água e nutrientes, em comparação com a condição de solo nu.

Ante o exposto se desenvolveu este trabalho com o objetivo de avaliar o efeito da erosividade da chuva e dos padrões de precipitação associados a diferentes tipos de preparo e cobertura do solo na erosão hídrica de um Argissolo Vermelho-Amarelo.

\section{MATERIAL E MÉTODOS}

\section{Caracterização da área experimental}

O experimento foi conduzido no Campo Experimental da Embrapa Agrobiologia, localizado no Município de Seropédica, RJ (coordenadas geográficas $22^{\circ} 46^{\prime}$ de latitude Sul e $43^{\circ} 41^{\prime}$ de longitude Oeste), em um solo classificado como Argissolo Vermelho-Amarelo (EMBRAPA, 1997). Cinco parcelas experimentais de perda de solo com dimensões de 22,0 x 3,5 m, que ocupavam o terço médio de uma encosta, com declividade de $0,09 \mathrm{~m} \mathrm{~m}^{-1}$ foram utilizadas. Na Tabela 1 se encontram algumas características físicas do solo da área de estudo.

Em virtude da área experimental estar há muito tempo sem utilização se realizou, inicialmente, uma escarificação mecânica até $0,4 \mathrm{~m}$ de profundidade, seguida de uma aração e duas gradagens em nível, cerca de duas semanas antes 
Tabela 1. Algumas características físicas e químicas do Argissolo Vermelho Amarelo em que foram implantadas as parcelas de perda de solo

\begin{tabular}{|c|c|c|c|c|c|c|c|c|c|c|}
\hline \multicolumn{2}{|c|}{ Horizonte } & \multicolumn{5}{|c|}{ Composição granulométrica TFSA (\%) } & \multirow{2}{*}{\multicolumn{2}{|c|}{ Grau de floculação (\%) }} & \multirow{2}{*}{\multicolumn{2}{|c|}{ Silte/Argila }} \\
\hline Símb. & Prof. (cm) & Areia & $05 \mathrm{~mm})$ & Silte (0 & $2 \mathrm{~mm})$ & Argila total $(<2 \mu)$ & & & & \\
\hline A & $0-16$ & \multicolumn{2}{|c|}{58} & \multicolumn{2}{|c|}{15} & 26 & \multicolumn{2}{|c|}{27} & \multicolumn{2}{|c|}{0,59} \\
\hline$A B$ & $16-27$ & \multicolumn{2}{|c|}{50} & \multicolumn{2}{|c|}{14} & 36 & \multicolumn{2}{|c|}{19} & \multicolumn{2}{|c|}{0,38} \\
\hline BA & $27-46$ & \multicolumn{2}{|c|}{42} & \multicolumn{2}{|c|}{13} & 44 & \multicolumn{2}{|c|}{44} & \multicolumn{2}{|c|}{0,30} \\
\hline Bt1 & $46-90$ & \multicolumn{2}{|c|}{46} & \multicolumn{2}{|c|}{12} & 42 & \multicolumn{2}{|c|}{77} & \multicolumn{2}{|c|}{0,30} \\
\hline Bt2 & $90-117$ & \multicolumn{2}{|c|}{40} & \multicolumn{2}{|c|}{15} & 45 & \multicolumn{2}{|c|}{82} & \multicolumn{2}{|c|}{0,33} \\
\hline $\mathrm{B}+3$ & 117-155 & \multicolumn{2}{|c|}{30} & \multicolumn{2}{|c|}{12} & 58 & \multicolumn{2}{|c|}{99} & \multicolumn{2}{|c|}{0,21} \\
\hline \multirow{2}{*}{ Símb. } & \multirow{2}{*}{$\mathrm{pH} \mathrm{H} \mathrm{H}_{2} \mathrm{O}$} & Al & $\mathrm{Ca}+\mathrm{Mg}$ & $\mathrm{Ca}$ & $\mathrm{Mg}$ & K & $\mathbf{P}$ & C & MO & $\mathbf{N}$ \\
\hline & & \multicolumn{4}{|c|}{$\mathrm{cmol}_{\mathrm{c}} \mathrm{dm}^{-3}$} & \multicolumn{2}{|c|}{$\mathrm{mg} \mathrm{dm}^{-3}$} & & \multicolumn{2}{|l|}{$\%$} \\
\hline A & 4,90 & 0,20 & 4,10 & 2,80 & 1,30 & 47,00 & 4,00 & 1,04 & 1,80 & 0,11 \\
\hline$A B$ & 5,00 & 0,20 & 3,70 & 2,00 & 1,70 & 20,00 & 3,00 & 0,85 & 1,46 & 0,10 \\
\hline BA & 5,10 & 0,00 & 3,40 & 2,30 & 1,10 & 14,00 & 1,00 & 0,48 & 0,83 & 0,06 \\
\hline Bt1 & 5,70 & 0,00 & 3,00 & 1,80 & 1,20 & 51,00 & 1,00 & 0,28 & 0,48 & 0,05 \\
\hline
\end{tabular}

do início do experimento, com o objetivo de se conferir certo grau de homogeneidade às camadas superficiais do solo antes da implantação das parcelas; após essas operações, cada parcela foi ocupada com os seguintes tratamentos:

- Mucuna: Preparo convencional do solo (uma aração e duas gradagens) em nível e plantio de Mucuna Cinza (Mucuna pruriens) em nível, com semeadura direta em sulcos espaçados $0,5 \mathrm{~m}$ e uma densidade de 5 sementes por metro linear, em sistema de quincôncio, ou seja, alternando a posição da semeadura em formato triangular;

- Crotalária: Preparo convencional do solo em nível e plantio de Crotalária (Crotalaria juncea) em nível, cuja semeadura feita em sulcos espaçados $0,5 \mathrm{~m}$ e na densidade de 20 sementes por metro linear;

- Milho em nível: Preparo convencional do solo em nível e Milho (Zea mays L.) BRS2110 da linha "compet” Bayer “seeds”, semeado no espaçamento de 1,0 m entre sulcos e 0,3 m entre plantas mantendo-se, após desbaste, duas plantas entre os espaçamentos, com as linhas dispostas em nível;

- Milho morro abaixo: Preparo convencional do solo no sentido do declive e plantio do mesmo híbrido de milho utilizado no tratamento anterior com o mesmo espaçamento, porém com as linhas de plantio dispostas de morro abaixo;

- Solo exposto: Preparo convencional do solo no sentido do declive e mantido sem cobertura durante a execução do experimento.

As semeaduras foram realizadas no dia 22/12/2004, data em que as coletas de enxurradas começaram a ser realizadas, no entanto, na parcela cultivada com mucuna foi necessário executar um replantio em 29/12/2004, em virtude de falhas significativas na germinação, comprometendo o estande; o mesmo procedimento foi adotado para os tratamentos Milho em Nível e Milho Morro a Baixo, sendo que nesses casos as semeaduras foram realizadas no dia 14/01/2005.

Para todos os tratamentos se realizou uma adubação de plantio, e se aplicou uma dosagem de $80 \mathrm{~kg} \mathrm{ha}^{-1}$ de $\mathrm{P}_{2} \mathrm{O}_{5}$ e $40 \mathrm{~kg} \mathrm{ha}^{-1}$ de $\mathrm{K}_{2} \mathrm{O}$, juntamente com $20 \mathrm{~kg} \mathrm{ha}^{-1}$ de micronutrientes (FTE BR12); a aplicação foi localizada nos sulcos de plantio e as fontes de $\mathrm{P}$ e $\mathrm{K}$ empregadas foram, respecti- vamente, Superfosfato Simples (20\% de $\left.\mathrm{P}_{2} \mathrm{O}_{5}\right)$ e Cloreto de Potássio $\left(60 \% \mathrm{~K}_{2} \mathrm{O}\right)$; a adubação aplicada foi baseada nos resultados revelados pela análise química de amostras coletadas na faixa de profundidade 0,0-0,4 m, de acordo com as recomendações do Manual de Adubação para o Estado do Rio de Janeiro (Almeida et al., 1988).

\section{Estudo das características das chuvas}

Para o armazenamento das magnitudes dos eventos de chuva ocorridos durante a condução do experimento, instalou-se um pluviógrafo digital do tipo pulso, o qual estava conectado a um Datalogger, previamente programado para armazenar valores de precipitação a cada minuto, e foi instalado próximo à área experimental. Após cada evento de chuva erosiva o dispositivo de memória era descarregado com o auxílio de um microcomputador e os dados eram então analisados para serem utilizados posteriormente.

De posse dos dados pluviográficos se realizou o cálculo do índice de erosividade $\mathrm{EI}_{30}$ e se identificaram os padrões das chuvas erosivas (Carvalho et al., 2005) utilizando-se o programa “Chuveros”, conforme Cogo et al. (2003).

Após a realização da classificação das chuvas em padrões e de posse dos respectivos valores de erosividade $\mathrm{EI}_{30}$, efetuou-se o cálculo da erosividade necessária para provocar o escoamento superficial de $1 \mathrm{~mm}$ de água, conforme Eq. 1.

$$
\overline{\mathrm{X}}=\frac{\mathrm{EI}_{30}^{1}}{\mathrm{~L}_{\mathrm{esc}}}
$$

em que:

$\overline{\mathrm{X}}$ - erosividade necessária para causar escoamento superficial de 1,0 mm de lâmina de água em cada parcela, para grupo de chuvas erosivas de mesmo padrão, MJ mm ha-1 $\mathrm{h}^{-1} \mathrm{~mm}^{-1}$

$\mathrm{EI}_{30}^{1}$ - erosividade $\left(\mathrm{EI}_{30}\right)$ média para chuvas de mesmo padrão, MJ mm ha ${ }^{-1} \mathrm{~h}^{-1}$

$\mathrm{L}_{\text {esc }}$ - Lâmina média escoada em cada parcela para chuvas erosivas de mesmo padrão, mm

\section{Quantificação da erosão hídrica}

Realizaram-se as coletas de enxurradas sempre após cada evento de chuva capaz de proporcionar escoamento 
superficial. Os procedimentos detalhados da montagem das parcelas experimentais, da coleta do sedimento e do material em suspensão, são apresentados por Cruz (2006).

Para determinação da massa de solo presente nos sedimentos, as amostras foram acondicionadas em estufa de circulação forçada a $60^{\circ} \mathrm{C}$, até que se atingisse massa constante, conforme metodologia utilizada também por Souza (2002) e Carvalho et al. (2003).

As perdas totais de solo foram determinadas somando-se a massa de solo presente na suspensão, extrapolada para o volume total escoado, com a massa de solo do sedimento, extrapolada para $40 \mathrm{~L}$, correspondendo ao volume deixado na caixa no momento da coleta do sedimento.

\section{RESULTADOS E DISCUSSÃO}

\section{Lâmina precipitada, erosividade e padrão das precipitações}

A Tabela 2 apresenta o registro das precipitações diárias ocorridas no período estudado, os índices $\mathrm{EI}_{30}$ e os padrões das precipitações. $\mathrm{O}$ total precipitado e o $\mathrm{EI}_{30}$ acumulado foram de $542,2 \mathrm{~mm}$ e de $1.269,9 \mathrm{MJ} \mathrm{mm} \mathrm{ha}^{-1} \mathrm{~h}^{-1}$, respectivamente.

Com exceção dos meses de fevereiro e abril, durante o período de execução do experimento a lâmina precipitada foi superior em relação às médias históricas apresentadas por Carvalho et al. (2005), que encontraram precipitações médias de 175, 110, 115, 101 e $44 \mathrm{~mm}$, respectivamente, para os meses de janeiro a maio; porém, os índices $\mathrm{EI}_{30}$ se apre-

Tabela 2. Lâminas totais precipitadas, índices de erosividade $\mathrm{EI}_{30}$ e padrões de precipitação das chuvas ocorridas durante a execução do experimento

\begin{tabular}{|c|c|c|c|c|}
\hline Data & $\begin{array}{l}\text { Precipitação } \\
(\mathrm{mm})\end{array}$ & $\begin{array}{l}\text { Precipitação } \\
\text { Acumulada } \\
\text { (mm) }\end{array}$ & $\begin{array}{c}\mathrm{El}_{30} \\
\left(\mathrm{MJ} \mathrm{mm} h \mathrm{~h} \mathrm{~h}^{-1}\right)\end{array}$ & $\begin{array}{c}\text { Padrão de } \\
\text { precipitação* }\end{array}$ \\
\hline $24 / 12 / 04$ & 38,1 & 38,1 & 26,8 & 1 \\
\hline 25/12/04 & 20,5 & 58,6 & 88,2 & 1 \\
\hline 27/12/04 & 21,0 & 79,6 & 16,9 & 2 \\
\hline $11 / 01 / 05$ & 29,0 & 108,6 & 232,7 & 1 \\
\hline $12 / 01 / 05$ & 29,0 & 137,6 & 177,1 & 1 \\
\hline $13 / 01 / 05$ & 5,0 & 142,6 & 1,8 & 1 \\
\hline $19 / 01 / 05$ & 44,0 & 186,6 & 72,7 & 1 \\
\hline 23/01/05 & 48,0 & 234,6 & 88,7 & 3 \\
\hline 27/01/05 & 42,0 & 276,6 & 39,5 & 1 \\
\hline 28/01/05 & 7,0 & 283,6 & 2,1 & 3 \\
\hline 05/02/05 & 21,6 & 305,2 & 16,5 & 3 \\
\hline 04/03/05 & 48,0 & 353,2 & 32,2 & 1 \\
\hline $16 / 03 / 05$ & 5,5 & 358,7 & 0,2 & 1 \\
\hline $19 / 03 / 05$ & 23,0 & 381,7 & 53,1 & 1 \\
\hline 25/03/05 & 37,0 & 418,7 & 67,3 & 2 \\
\hline 26/03/05 & 11,5 & 430,2 & 5,1 & 2 \\
\hline 29/03/05 & 16,3 & 446,5 & 131,5 & 1 \\
\hline 01/04/05 & 22,0 & 468,5 & 15,6 & 1 \\
\hline 05/04/05 & 15,0 & 483,5 & 32,5 & 2 \\
\hline 02/05/05 & 8,7 & 492,2 & 2,6 & 2 \\
\hline 22/05/05 & 22,0 & 514,2 & 72,8 & 2 \\
\hline 25/05/05 & 28,0 & 542,2 & 92,5 & 1 \\
\hline Total & 542,2 & & $1.268,4$ & \\
\hline
\end{tabular}

sentaram com menores magnitudes em comparação com as informações apresentadas por esses autores, com exceção do mês de maio. Para os mesmos meses citados anteriormente, Carvalho et al. (2005) calcularam valores de $\mathrm{EI}_{30}$ de 956, 872, 763, 352 e $144 \mathrm{MJ} \mathrm{mm} \mathrm{ha}^{-1} \mathrm{~h}^{-1}$, respectivamente.

Nesta análise, o mês de dezembro não foi considerado pelo fato da coleta de dados experimentais ter sido iniciada apenas no dia 24. Apesar das diferenças citadas nas lâminas precipitadas e nos índices de erosividade, esses valores são coerentes com os encontrados por Carvalho et al. (2005), considerando-se uma série histórica de pluviogramas de 1974 a 1980.

Nota-se, na Tabela 2 que, dentre as chuvas registradas durante o período de estudo, houve predominância de eventos de padrão avançado, tendo-se constatado 13 eventos com esta característica, dentre os 22 registrados; já os eventos de chuva de padrão de precipitação intermediário ocorreram 6 vezes e os eventos com padrão de precipitação atrasado, apenas 3; dos 542,2 mm precipitados entre 24/12/2004 e 25/05/ 2005, cerca de 64,6, 21,3 e 14,1\%, ocorreram, respectivamente, em eventos de precipitação de padrão avançado, intermediário e atrasado. Esses resultados, embora baseados apenas em uma parte do ano, seguem um padrão semelhante ao encontrado por Carvalho et al. (2005) que observaram, em média, por ano, que cerca de $61,01 \%$ das chuvas erosivas são de padrão avançado e cerca de $19,47 \%$ das chuvas erosivas são de padrão intermediário, sendo o mesmo percentual de chuvas de padrão atrasado.

Do índice de erosividade total observado (1.268,4 MJ mm ha-1 $\mathrm{h}^{-1}$ ), cerca de 75,9, 15,6 e 8,5\%, ocorreram, respectivamente, em eventos de precipitação de padrão avançado, intermediário e atrasado; desta forma, foi possível constatar que não apenas o padrão avançado constituiu aquele com maior incidência mas, também, o que proporcionou maiores índices de erosividade.

Apresentam-se na Tabela 3, os valores de erosividade acumulada para as precipitações de diferentes padrões necessários para causar o escoamento superficial de 1,0 mm; notase, na Tabela que, independente do padrão de chuva erosiva, as maiores demandas de energia da chuva para causar uma lâmina de escoamento de 1,0 mm, foram observadas na parcela ocupada com o tratamento Crotalária.

Enfatizando o que já foi discutido, a cobertura vegetal proporcionada pelo plantio de crotalária e seus resíduos deixados sobre a superfície do terreno após o corte, serviram de proteção contra o efeito do impacto das gotas de chuva sobre a superfície do solo; assim, para que fosse formado o es-

Tabela 3. Erosividade necessária para causar escoamento superficial de 1,0 $\mathrm{mm}\left(\mathrm{MJ} \mathrm{mm} \mathrm{ha-1} \mathrm{h}^{-1} \mathrm{~mm}^{-1}\right.$ ) para os diferentes padrões de precipitação e tratamentos estudados

\begin{tabular}{lccc}
\hline Tratamentos & Padrão avançado & $\begin{array}{c}\text { Padrão } \\
\text { intermediário }\end{array}$ & Padrão atrasado \\
Mucuna & 11,6 & 12,6 & 2,0 \\
Crotalária & 20,8 & 50,6 & 4,9 \\
Milho em Nível & 13,4 & 7,6 & 2,8 \\
Milho Morro Abaixo & 8,1 & 5,5 & 1,8 \\
Solo Exposto & 11,2 & 6,9 & 1,6 \\
\hline
\end{tabular}


coamento correspondente a uma lâmina média de 1,0 mm, foi conveniente maior quantidade de energia da chuva; por outro lado, o tratamento Milho Morro a Baixo foi aquele que apresentou a menor erosividade acumulada necessária para a formação do escoamento médio de $1,0 \mathrm{~mm}$, o que pode ser explicado pelo fato desse tratamento proporcionar maiores escoamentos superficiais, influenciados não só pelo selamento superficial ocasionado pelo impacto das gotas de chuva sobre o solo mas, também, pela baixa tensão de cisalhamento que a superfície do solo possuía, em função do seu preparo ter sido feito no sentido do declive.

Nota-se ainda na Tabela 3, que o padrão de chuva em que foi necessária a menor demanda de energia por mm escoado, para todos os tratamentos, foi o atrasado, fato que pode ser explicado em virtude de ser característica, desse tipo de chuva, a ocorrência do pico de maior intensidade de precipitação em um intervalo de $30 \mathrm{~min}\left(\mathrm{I}_{30}\right)$ no terço final da chuva erosiva. Como o índice $\mathrm{EI}_{30}$ é diretamente proporcional ao $\mathrm{I}_{30}$, no momento em que ocorria tal intensidade o solo já se encontrava saturado e, provavelmente, o escoamento superficial já havia sido iniciado, fazendo com que as lâminas escoadas fossem maiores diminuindo, então, a relação entre $\mathrm{EI}_{30}$ e a lâmina escoada (Eltz et al., 2003). Os tratamentos Crotalária e Solo Exposto apresentaram, respectivamente, o maior e o menor valor de energia específica nas condições do trabalho, evidenciando a importância da cobertura do solo na dissipação da energia cinética das chuvas e, em conseqüência, na minimização do processo erosivo.

\section{Escoamento superficial e perda de solo}

Na Tabela 4 se encontram as lâminas escoadas e as perdas de solo em cada parcela experimental, decorrentes das precipitações durante a execução do experimento. As perdas totais de água foram de 161,2, 68,5, 154,5, 215,5 e 209,1 mm, respectivamente, para os tratamentos Mucuna, Crotalária, Milho em Nível, Milho Morro a Baixo e Solo Exposto.

As diferenças entre os tratamentos estão relacionadas aos preparos do solo empregados e às taxas de evolução das coberturas do solo, já que para os tratamentos Solo Exposto e Milho Morro a Baixo foram empregadas operações de preparo do solo no sentido do declive, o que fez com que a velocidade de escoamento da água sobre o solo fosse aumentada, acarretando aumento nas perdas totais de água em detrimento dos demais tratamentos.

As coberturas do solo foram determinantes na redução das perdas de água, uma vez que até o momento em que foi realizado o corte das plantas, para os tratamentos Mucuna, Crotalária, Milho em Nível e Milho Morro a Baixo, respectivamente cerca de 96,7, 94,8, 97,8 e 98,1\% do total das lâminas escoadas já haviam sido registrados.

Os valores totais de perda de solo variaram de 1.862,2 a $12.399,8 \mathrm{~kg} \mathrm{ha}^{-1}$ e corresponderam, respectivamente, aos tratamentos Crotalária e Milho Morro a Baixo. Ainda na Tabela 4, é possível perceber que os tratamentos cujo preparo do solo foi realizado em nível, indicaram os menores valores de perda de solo, exceto para o tratamento Mucuna, que gerou perda total de solo similar à perda gerada pelo tratamento Solo Exposto. De acordo com Amorim (2003), esta redução se deve ao fato do cultivo em nível propiciar menor velocidade e tensão cisalhante do escoamento superficial, reduzindo sua capacidade de transporte e de desprendimento das partículas de solo.

Tabela 4. Escoamento superficial (Es em mm) e perda de solo (Ps em kg ha-1) nas parcelas experimentais entre 24/12/2004 e 25/05/2005

\begin{tabular}{|c|c|c|c|c|c|c|c|c|c|c|}
\hline \multirow{2}{*}{ Data } & \multicolumn{2}{|c|}{ Mucuna $^{1}$} & \multicolumn{2}{|c|}{ Crotalária $^{1}$} & \multicolumn{2}{|c|}{ Milho em Nível ${ }^{2}$} & \multicolumn{2}{|c|}{ Milho Morro Abaixo² } & \multicolumn{2}{|c|}{ Solo Exposto } \\
\hline & Es & Ps & Es & Ps & Es & Ps & Es & Ps & Es & Ps \\
\hline $24 / 12 / 04$ & 30,9 & 259,7 & 4,8 & 27,5 & 8,7 & 62,6 & 21,4 & 187,0 & 10,4 & 122,6 \\
\hline $25 / 12 / 04$ & 11,2 & 744,2 & 13,1 & 435,9 & 16,2 & 503,6 & 15,4 & 649,5 & 10,4 & 242,3 \\
\hline $27 / 12 / 04$ & 7,7 & 241,2 & 3,5 & 64,4 & 9,6 & 151,4 & 12,1 & 237,3 & 10,4 & 141,5 \\
\hline $11 / 01 / 05$ & 2,5 & 113,3 & 1,3 & 89,5 & 3,1 & 94,3 & 6,2 & 230,4 & 3,2 & 36,8 \\
\hline $12 / 01 / 05$ & 15,5 & 655,8 & 12,1 & 397,1 & 16,9 & 399,2 & 25,0 & 648,5 & 10,4 & 276,0 \\
\hline $13 / 01 / 05$ & 0,1 & 0,2 & 0,0 & 0,0 & 0,0 & 0,0 & 0,6 & 1,2 & 0,1 & 0,2 \\
\hline $19 / 01 / 05$ & 19,5 & 89,3 & 2,9 & 7,5 & 17,8 & 80,7 & 20,2 & 274,8 & 17,5 & 70,4 \\
\hline $23 / 01 / 05$ & 36,3 & $4.732,8$ & 20,2 & 802,9 & 31,3 & $2.343,3$ & 39,9 & $7.095,2$ & 45,2 & $4.044,4$ \\
\hline $27 / 01 / 05$ & 19,5 & 73,9 & 6,0 & 10,8 & 27,9 & 75,9 & 24,7 & $1.582,0$ & 26,7 & 118,8 \\
\hline $28 / 01 / 05$ & 1,6 & 4,1 & 0,1 & 0,0 & 0,7 & 2,5 & 2,3 & 30,5 & 1,6 & 7,5 \\
\hline 05/02/05 & 2,9 & 17,3 & 0,2 & 5,3 & 3,5 & 8,8 & 6,5 & 366,5 & 10,3 & 107,5 \\
\hline 04/03/05 & 0,8 & 0,5 & 0,5 & 0,2 & 0,1 & 8,0 & 1,4 & 22,0 & 4,2 & 63,7 \\
\hline $16 / 03 / 05$ & 0,0 & 0,0 & 0,1 & 0,4 & 0,0 & 0,0 & 3,4 & 164,5 & 7,0 & 74,2 \\
\hline $19 / 03 / 05$ & 0,6 & 2,6 & 0,1 & 0,3 & 0,1 & 0,1 & 5,7 & 361,3 & 10,3 & 44,9 \\
\hline $25 / 03 / 05$ & 7,0 & 41,6 & 0,0 & 0,0 & 13,1 & 95,7 & 20,2 & 279,9 & 15,0 & 846,9 \\
\hline $26 / 03 / 05$ & 0,3 & 0,5 & 0,0 & 0,0 & 0,2 & 0,9 & 1,8 & 4,9 & 0,8 & 3,7 \\
\hline $29 / 03 / 05$ & 1,0 & 16,3 & 0,1 & 0,0 & 1,0 & 36,8 & 1,8 & 199,5 & 1,8 & 385,2 \\
\hline 01/04/05 & 2,6 & 13,1 & 0,0 & 0,0 & 0,9 & 7,5 & 2,7 & 47,4 & 5,6 & 224,2 \\
\hline 05/04/05 & 0,3 & 0,5 & 0,0 & 0,0 & 0,0 & 0,0 & 0,1 & 0,0 & 0,0 & 0,0 \\
\hline 02/05/05 & 0,1 & 1,7 & 0,0 & 0,0 & 0,0 & 0,0 & 0,0 & 0,0 & 0,1 & 0,0 \\
\hline $22 / 05 / 05$ & 0,3 & 1,5 & 0,4 & 3,8 & 0,1 & 0,1 & 0,1 & 2,5 & 0,8 & 21,3 \\
\hline $25 / 05 / 05$ & 0,8 & 2,4 & 3,1 & 16,5 & 3,1 & 5,7 & 3,9 & 14,9 & 17,5 & 196,7 \\
\hline Total & 161,2 & $7.012,5$ & 68,5 & $1.862,1$ & 154,5 & $3.877,1$ & 215,5 & $12.399,8$ & 209,1 & $7.028,8$ \\
\hline
\end{tabular}


Referidos resultados corroboram com o postulado por Bertoni \& Lombardi Neto (2005), ao afirmarem que o cultivo em nível pode reduzir, em até $50 \%$, as perdas de solo em relação ao cultivo morro abaixo. O fato do tratamento Crotalária ter proporcionado nível de cobertura do solo de 85,8\% aos 56 dias após semeadura (DAS), e o tratamento Mucuna ter apresentado $76,7 \%$ de cobertura do solo aos 76 DAS (Cruz, 2006), fez com que as perdas de água totais para o tratamento Crotalária fossem cerca de 2,4 vezes menores que as observadas para o tratamento Mucuna.

O reduzido valor de Ps para o tratamento Crotalária em relação aos demais tratamentos permitiu constatar que esse tipo de cobertura contribui para uma dissipação maior da energia cinética das chuvas, possibilitando uma diminuição do processo de desagregação das partículas de solo e, conseqüentemente, redução nas perdas por erosão, em entressulcos; por outro lado, os tratamentos ocupados com a cultura do milho evidenciaram a importância do emprego do preparo do solo em nível, uma vez que se observou uma Ps de $3.877,1 \mathrm{~kg} \mathrm{ha}^{-1}$, para este tratamento em relação aos 12.399,8 $\mathrm{kg} \mathrm{ha}^{-1}$, para o milho cultivado morro abaixo. Em relação aos Es, esses foram de 154,5 e 215,5 mm, respectivamente, para os mesmos tratamentos. Ressalta-se que em ambos os tratamentos as porcentagens de cobertura do solo com a cultura do milho não ultrapassaram os $40 \%$ por ocasião do corte (Cruz, 2006).

Quanto aos tratamentos cujo preparo do solo foi realizado no sentido do declive, foi possível perceber que no tratamento Milho Morro a Baixo houve intensificação do processo de erosão nos sulcos, já que o plantio foi realizado em sulcos dispostos no sentido do declive fazendo com que a água escoasse com maior velocidade aumentando, assim, o volume escoado; já para o tratamento Solo Exposto, houve grande interferência do processo de erosão em entressulcos, uma vez que o impacto das gotas de chuva diretamente sobre a superfície do solo fazia com que ocorressem o desprendimento das partículas do solo e o seu posterior carreamento, resultados que estão de acordo com Cassol \& Lima (2003) que, estudando as perdas de solo e água em um Argissolo Vermelho submetido a chuvas naturais, verificaram que em sistemas de semeadura sem preparo do solo e por isso mesmo com alta taxa de cobertura, as perdas de água nas áreas em entressulcos são consideravelmente reduzidas em relação ao solo descoberto.

Quando comparadas as lâminas totais escoadas da parcela padrão (solo exposto) com as das demais parcelas, nota-se que apenas a lâmina total escoada da parcela com tratamento Milho Morro a Baixo foi maior que a lâmina escoada da parcela Solo Exposto (Tabela 3), cujo resultado diverge dos obtidos por Amorim (2003), pois este autor observou que o cultivo do milho morro abaixo foi responsável pela redução de aproximadamente $68 \%$ da lâmina escoada em relação à parcela padrão; este fato, no entanto, demonstra a complexidade que o estudo do processo erosivo possui, dada à quantidade de fatores que influenciam neste fenômeno, e ainda reforça a necessidade de serem realizados mais estudos de campo sobre este fenômeno com vistas à validação de modelos de predição de perda de solo a serem aplicados no Brasil.
Verifica-se, ainda, que a cobertura do solo, associada ao preparo em nível, foi eficiente na redução das perdas de água em relação ao preparo do solo morro abaixo mantido descoberto (Crotalária - 67,2\%; Milho em Nível - 26,1\% e Mucuna - 22,9\%); por outro lado, o tratamento Milho Morro a Baixo proporcionou um aumento nas perdas de água em relação ao tratamento Solo Exposto, de aproximadamente 2,3\%; nota-se também, nas Tabelas 2 e 4, que o evento de precipitação que ocasionou os maiores escoamentos superficiais ocorreu no dia 23/01/2005, porém o índice $\mathrm{EI}_{30}$ calculado para este evento foi apenas o quinto maior dentre os listados na Tabela 2, ou seja, o pico de maior intensidade de precipitação se deu no terço final da chuva erosiva, fazendo com que a capacidade de infiltração da água no solo seja reduzida neste momento crítico da chuva, o que acarretou aumento no volume de escoamento superficial; por sua vez, a chuva com maior índice de erosividade ocorreu após um veranico de 14 dias, o que fez com que as lâminas escoadas em todas as parcelas não fossem as maiores, já que um solo com menor conteúdo de umidade possui maior capacidade de infiltração, reduzindo o volume do escoamento superficial; esses fatos ressaltam a grande importância que também apresentam os fatores como umidade antecedente do solo e padrão de precipitação na magnitude dos processos erosivos, conforme também observaram Lima et al. (2005).

\section{CONCLUSÕES}

1. Para os padrões avançado, intermediário e atrasado, foram observados, respectivamente, 64,6, 21,3 e 14,1\% da lâmina precipitada e 76,0, 15,5 e 8,5\% da erosividade acumulada no período de estudo.

2. Considerando-se todos os tratamentos, conclui-se que os eventos de precipitação caracterizados como avançado, intermediário e atrasado, foram responsáveis por 62,6, 11,8 e $25,6 \%$ das perdas de água e por 35,1, 6,6 e 58,3 das perdas de solo, respectivamente.

3. As perdas de solo foram mais influenciadas pelo emprego dos diferentes tratamentos que as perdas de água.

4. Os tratamentos Crotalária e Milho morro abaixo foram aqueles que apresentaram, respectivamente, as menores e maiores perdas de solo e água.

5. O uso da Crotalária como cobertura do solo, reduziu em $67,2 \%$ e em $85,0 \%$ as perdas de água e solo, respectivamente, quando comparado com o cultivo do Milho morro abaixo.

\section{LITERATURA CITADA}

Almeida, D. L.; Santos, G. A.; De-Polli, H.; Cunha, L. H; Freire, L. R.; Amaral Sobrinho, N. M. B.; Pereira, N. N. C.; Eira, P. A.; Bloise, R. M.; Salek, R. C. Manual de adubação para o Estado do Rio de Janeiro. Itaguaí: Universidade Rural. 1988. 179p. Coleção Universidade Rural. Ciências Agrárias, n.2.

Amorim, R. S. S. Avaliação dos modelos de predição da erosão hídrica USLE, RUSLE e WEPP para condições edafoclimáticas brasileiras. Viçosa: UFV, 2003. 116p. Tese Doutorado 
Andrello, A. C.; Appoloni, C. R.; Guimarães, M. F. Uso do Césio-137 para avaliar taxas de erosão em cultura de soja, café e pastagem. Revista Brasileira de Ciência do Solo, v.27, p.223229, 2003.

Bertol, I.; Guadagnin, J. C.; Casol, P. C.; Amaral, A. J.; Barbosa, F. T. Perdas de fósforo e potássio por erosão hídrica em um Inceptisol sob chuva natural. Revista Brasileira de Ciência do Solo, v.28, p.485-494, 2004.

Bertol, I.; Melo, E. L.; Guadagnin, J. C.; Zaparolli, A. L. V; Carrafa, M. R. Nutrient losses by water erosion. Scientia Agrícola, v.60, n.3, p.581-586, 2003.

Bertoni, J.; Lombardi Neto, F. Conservação do solo. 5.ed. São Paulo: Ícone, 2005. 355p.

Carvalho, D. F.; Montebeller, C. A.; Cruz, E. S. da; Lana, A. M. Q.; Silva, W. A. Efeito da cobertura morta e do preparo do terreno nas perdas de solo e água em um Argissolo VermelhoAmarelo. Revista Engenharia na Agricultura, v.11, n.1-4, p.1522, 2003.

Carvalho, D. F.; Montebeller, C. A.; Franco, E. M.; Ceddia, M. B.; Lana, A. M. Q. Perdas de solo e água em um Argissolo Vermelho Amarelo, submetido a diferentes intensidades de chuva simulada. Revista Brasileira de Engenharia Agrícola e Ambiental, v.6, n.3, p.385-389, 2002.

Carvalho, D. F.; Montebeller, C. A.; Franco, E. M.; Valcarcel, R.; Bertol, I. Padrões de precipitação e índices de erosividade para as chuvas de Seropédica e Nova Friburgo, RJ. Revista Brasileira de Engenharia Agrícola e Ambiental, v.9, n.1, p.7-14, 2005.

Cassol, E. A.; Cantalice, J. R. B.; Reichert, J. M.; Mondardo, A. Escoamento superficial e desagregação do solo em entressulcos em solo franco-argilo-arenoso com resíduos vegetais. Pesquisa Agropecuária Brasileira, v.39, n.7, p.685-690, 2004.

Cassol, E. A.; Lima, V. L. Erosão em entressulcos sob diferentes tipos de preparo e manejo do solo. Pesquisa Agropecuária Brasileira, v.38, n.1, p.117-124, 2003.

Cogo, C. M.; Eltz, F. L. F.; Cassol, A.; Santos, M. V. Erosividade das chuvas de Uruguaiana, RS, determinada pelo índice EI30, no período de 1963-1990. In: Congresso Brasileiro de Ciência do Solo, 29, 2003, Ribeirão Preto. Solo: Alicerce dos sistemas de produção. Resumos Expandidos... Ribeirão Preto: UNESP, 2003. CD-Rom.

Cruz, E. S. Influência do preparo do solo e de plantas de cobertura na erosão hídrica de um Argissolo Vermelho-Amarelo. Seropédica: UFRRJ, 2006, 58p. Dissertação Mestrado

Eltz, F. L. F.; Mehl, H. U.; Reichert, J. M. Perdas de solo e água em entressulcos em um Argissolo Vermelho-Amarelo submetido a quatro padrões de chuva. Revista Brasileira de Ciência do Solo, v.25, p.485-493, 2003.

EMBRAPA - Empresa Brasileira de Pesquisa Agropecuária. Centro Nacional de Pesquisa de Solos. Manual de métodos de análise de solo. Rio de Janeiro: Embrapa CNPS, 1997. 212p.
Flanagan, D. C.; Foster, G. R.; Moldenhauer, W. C. Storm pattern effect on infiltration, runoff and erosion. Transactions of the ASAE, v.31, n.2, p.414-420, 1988.

Foster, G. R. Modeling the erosion process. In: Hann, C. T.; Johnson, H. P.; Brakensiek, D. L. (ed.). Hydrologic modeling of small watersheds, St. Joseph: American Society of Agricultural Engineering, 1982. p.297-380. Monograph, 5.

Lal, R. Global soil erosion by water and carbon dynamics. In: Lal, R.; Kimble, J.; Levine, E.; Stewart, B. Soils and global change. In: Advances in Soil Science. Florida: CRC/Lewis Publishers. 1995, p. 131-142.

Leite, D.; Bertol, I.; Guadagnin, J. C.; Santos, E. J.; Ritter, S. R. Erosão hídrica em um Nitosolo Háplico submetido a diferentes sistemas de manejo sob chuva simulada. I - Perdas de água e solo. Revista Brasileira de Ciência do Solo, v.28, p.10331044, 2004.

Lima G. L.; Aquino, R. F.; Silva, M. L. N.; Mello, C. R. Perdas por erosão hídrica em Cambissolo e Latossolo sob três padrões de chuvas erosivas para Lavras, MG. In: Congresso Brasileiro de Ciência do Solo, 30, 2005, Recife. Resumos expandidos... Recife: UFRPE, 2005. CD-Rom.

Nuñes, J. E. V.; Amaral Sobrinho, N. M. B.; Mazur, N. Conseqüências de diferentes sistemas de preparo do solo sobre a distribuição química e perdas de fósforo de um Argissolo. Bragantia, v.62, n.1, p.101-109. 2003.

Oliveira, J. R. Perdas de solo, água e nutrientes em um Argissolo Vermelho-Amarelo, sob diferentes padrões de chuva simulada. Seropédica: UFRRJ, 2007. 52p. Dissertação Mestrado

Pereira, S. B.; Pruski, F. F.; Silva, D. D.; Matos, A. T. Desprendimento e arraste do solo pelo escoamento superficial. Revista Brasileira Engenharia Agrícola e Ambiental, v.7, n.3, p.423-429, 2003.

Pimental, D.; Harvey, C.; Resosudarmo, P.; Sinclair, K.; Kurz, D.; Mcnair, M.; Crist, S.; Shprit, Z. L.; Fitton, L.; Saffouri, R.; Blair, R. Environmental and economic costs of soil erosion and conservation benefits. Science, v.267, p.1117-1124, 1995.

Silva, C. G.; Alves Sobrinho, T.; Vitorino, A. C. T.; Carvalho, D. F. Atributos físicos, químicos e erosão hídrica em entressulcos sob chuva simulada, em sistema de plantio direto e convencional. Engenharia Agrícola, v.25, n.1, p.144-153, 2005.

Souza, J. M. P. F. Perdas por erosão e características físico-hídricas de Latossolo em função do preparo do solo em oleráceas no ambiente de Mar de Morros, Paty do Alferes, RJ. Seropédica: UFRRJ, 2002. 83p. Dissertação Mestrado

Tolk, J. A.; Howell, T. A.; Evett, S. R. Effect of mulch, irrigation, and soil type on water use and yield of maize. Soil \& Tillage Research, v.50, p.137-147. 1999.

Vinsentin, D.; Bertol, I.; Amaral, A. J.; Carrafa, M. R.; Zoldan Júnior, W. A. Erosão hídrica em quatro cultivos sob chuva natural. In: Reunião Brasileira de Manejo e Conservação do Solo e da Água, 14, 2002, Cuiabá. Resumos Expandidos... Cuiabá: UFMT, 2002. CD Rom. 